\title{
Combined effect of temperature and salinity on osmoregulation of juvenile and subadult Penaeus stylirostris
}

\author{
P. Lemaire ${ }^{a}$, E. Bernard ${ }^{a}$, J. A. Martinez-Paz ${ }^{b}$ and L. Chim ${ }^{a, *}$ \\ a Institut Français de Recherche pour l'Exploitation de la Mer (IFREMER), Quai des Scientifiques, B.P. 2059, \\ 98846 Nouméa, New Caledonia \\ b Universidad de Santiago, Faculdad de Biologia, Departamento de Biologia Vegetal, Santiago 15706, Spain \\ *: Corresponding author : Tel.: +687-285-171; fax: +687-287-857; email: liet.chim@ifremer.fr
}

\begin{abstract}
:
In New Caledonia, the "syndrome 93," which results in mass mortalities of farmed shrimp Penaeus stylirostris, occurs during the transitional and the cold seasons. The transitional season is characterized by an important fall in the average water temperature from 28 to $19{ }^{\circ} \mathrm{C}$ in 2 weeks. Besides this marked temperature fall, there are also nyctemeral temperature changes of up to $7{ }^{\circ} \mathrm{C}$ in $12 \mathrm{~h}$. The cold season is characterized by an average water temperature of $19{ }^{\circ} \mathrm{C}$ with extreme lows of $14{ }^{\circ} \mathrm{C}$. The objective of this study was to determine the effect of temperature and its variations on the osmoregulatory capacity of juvenile (7-10 $\mathrm{g}$ average weight) and subadult (25 $\mathrm{g}$ average weight) shrimps subjected to conditions of different salinity. A reduction in temperature level resulted in a decreased osmoregulatory capacity (OC) (defined as the difference between the osmolality of the haemolymph and that of sea water) at low salinity (hyper-CO) and at high salinity (hypo-CO), respectively, below and above the isoosmotic point (26.2 ppt). In subadult shrimps, the hyper-CO was affected when temperature dropped from 26 to $22{ }^{\circ} \mathrm{C}$. The hypo-CO was modified only when temperature decreased down to $15{ }^{\circ} \mathrm{C}$. Furthermore, the sensitiveness of osmoregulation to temperature changes was dependent on the developmental stage of the shrimp. Subadults were more sensitive than juvenile animals.
\end{abstract}

The value of the isoosmotic point, which did not depend on the shrimp developmental stage, increased when temperature decreased to 17 or $15^{\circ} \mathrm{C}$.

Our results provide an additional explanation of the "syndrome 93" and display the unfavourable influence of marked temperature drop on shrimp health. Our research could provide a possibility of seeking a nutritional and/or genetic solution to improve the capacity of the shrimps to maintain their homeostasis within a rearing medium with fluctuating temperatures.

Author Keywords: Shrimp; Penaeus stylirostris; Osmoregulatory capacity; Salinity; Temperature 


\section{Introduction}

The shrimp Penaeus stylirostris originates from the Pacific coast between the north of Peru and the north of Mexico. It is commercially farmed in South America especially in Mexico

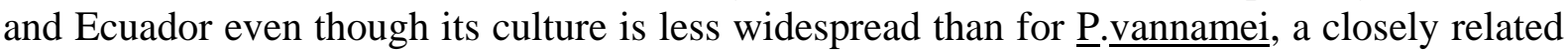

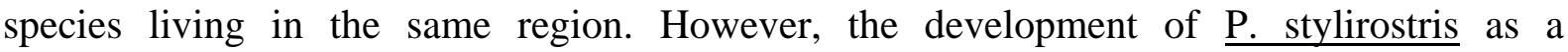
commercially farmed species is limited because this species is very sensitive to the IHHN virus. Through the selection of a strain of P.stylirostris (SPR43) resistent to the IHHN virus, IFREMER has contributed to the development of the aquacultural production of this species, especially in New Caledonia. Production in New Caledonia, which started in the early '80s, has now reached 2000 tonnes per year. Most recent forecasts for the year 2005 are 5000 tonnes of annual output. The farming of P.stylirostris in New Caledonia is subjected to two clearly differentiated seasons with average water temperatures of $29^{\circ} \mathrm{C}$ and $19^{\circ} \mathrm{C}$, respectively between April and September and between October and May. Within these average temperatures, nyctemeral fluctuations can reach $7^{\circ} \mathrm{C}$. The seasons of abrupt water temperature changes correspond to shrimp mass mortalities known as "syndrome 93" (Mermoud et al., 1998). Apart from the decreased yield originating from the high mortality related to "syndrome 93", the cold season is also characterized by the production of animals of significantly lower quality. They often have a soft cuticle (making it difficult to peel when cooked) and a "red head" (autolysis of the hepato-pancreas forming a visible red stain under the cephalothorax). The objective of this research was to observe the effect of the rearing water temperature changes on the osmoregulatory capacity (Charmantier et al.,1988; 1989) of the shrimp P.stylirostris. A better understanding of the effect of water temperature fluctuations on shrimp osmoregulatory capacity should give us elements of solutions to the problems encountered in New Caledonia at the beginning of and during the cold season. Furthermore, these results could be useful for shrimp farms in other regions of the world which have marked seasons, notably regarding the pond water temperature.

\section{Materials and methods}

\subsection{Shrimps}

The shrimps, Penaeus stylirostris (Stimpson, 1874), used in our the experiments were reared in $500 \mathrm{~m}^{2}$ earthen ponds at the Tropical Aquaculture Laboratory (IFREMER, Centre Océanologique du Pacifique, Tahiti, French Polynesia) according to the methods described by AQUACOP (1984). This population of shrimps is of Mexican origin and was imported by the IFREMER Centre in 1972 and has been reared for more than 30 generations (AQUACOP, 1984). One week prior to the experiment, the shrimps were captured using a castnet and were maintained in a flow-through $2 \mathrm{~m}^{3}$ tank at a maximum density of 50 shrimps per square metre. They were fed ad libitum twice a day with local commercial dry pellet feed.

Only the shrimps in C and D0 molting stages were sampled to measure haemolymph osmotic pressure. Molting stages were determined by microscopical examination of antennal scales according to the method of Drach and Tchernifovtzeff (1967).

The shrimps were kept starved for 8 hours before sampling their haemolymph.

\subsection{Acclimation of the shrimps to temperature and salinity}

The water salinity of the experimental tanks was slowly modified by 1.5 ppt every hour. Salinities higher and lower than 35 ppt were obtained by respectively adding natural sea salt and natural fresh water (spring water). This phase of acclimation to salinity was limited to 24 hours. After this, the water temperature was lowered by $0.5^{\circ} \mathrm{C}$ every hour till the value of the 
temperature to be tested. Finally the shrimps were maintained for 24 hours under the final experimental salinity and temperature conditions before sampling.

\subsection{Aquaria}

The experiments were carried out in 8 polyester tanks of 70 litres capacity, individually equipped with a water recirculating system (Fig.1). Each tank was fitted out with its own pump (Eheim ${ }^{\circledR}, 3001 . h^{-1}$ ) for recirculating the water. The pumps were immersed in a freshwater container thermoregulated by a cryostat (Variostat $\left.{ }^{\circledR}\right)$. By thermal exchange through the body of the pump, the rearing water was cooled to the desired temperature. The salinity of each tank was independently adjusted. Experiments were thus conducted at temperatures and salinities ranging respectively from $15^{\circ} \mathrm{C}$ to $28^{\circ} \mathrm{C}$ and from 5 ppt to $40 \mathrm{ppt}$.

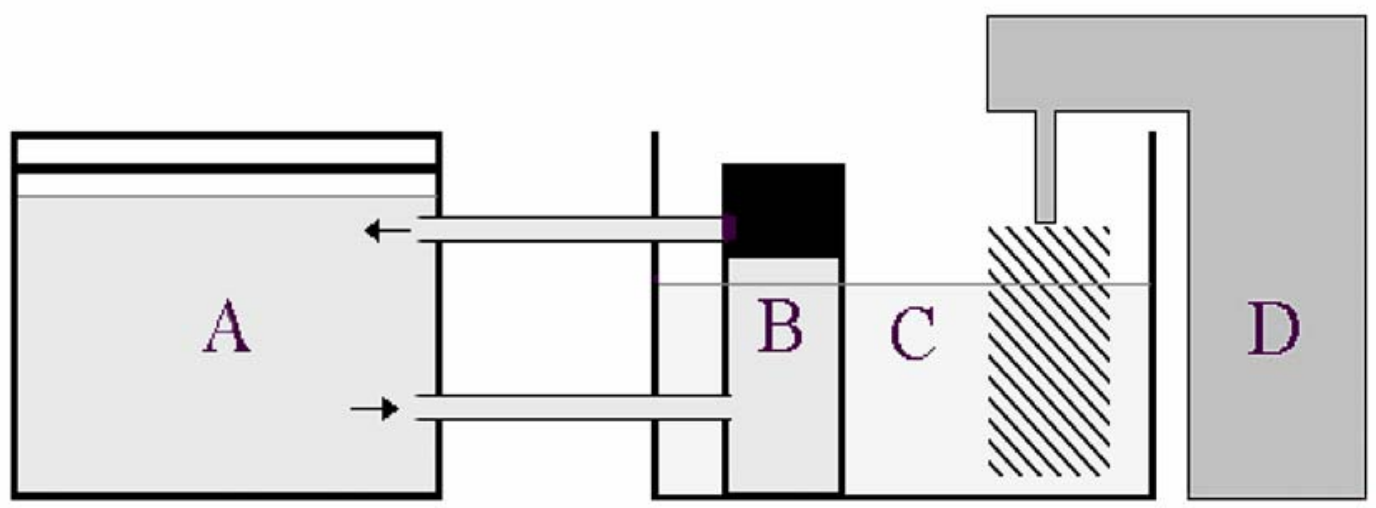

Fig 1. Schematic view of an experimental rearing tank (A) with the water recirculating system provided by a pump (B) immersed in water (C) thermoregulated by a cryostat (D)

\subsection{Osmolality analysis}

For haemolymph sampling, the needle of a $1 \mathrm{ml}$ hypodermic syringe was inserted into the ventro-lateral sinus of the cephalothorax. The osmolality of the haemolymph and of the rearing water are expressed in $\mathrm{m} 0 \mathrm{sm} \cdot \mathrm{kg}^{-1}$. Osmolality was measured with a Wescor ${ }^{\circledR}$ vapor pressure osmometer, model 5500, utilizing a $10 \mu \mathrm{l}$ sample on a $6.35 \mathrm{~mm}$ diameter filter paper disc. The fresh weight of the shrimp was determined after drying it on absorbent paper and sampling the haemolymph. The osmoregulatory capacity (OC) corresponds to the difference between the haemolymph osmolality and the external medium osmolality (Charmantier et al, 1989). The hypo-osmoregulatory capacity (hypo-OC) and the hyper-osmoregulatory capacity (hyper-OC) refer respectively to the OC above and below the iso-osmotic point.

In a preliminary work we determined the linear function between water salinity expressed in ppt and in mOsm. $\mathrm{kg}^{-1}$. This function is described by the equation $\mathrm{Y}=28.939 \mathrm{x}-23.103$ with the salinity expressed in ppt $(\mathrm{x})$ in abscissa and the salinity expressed in $\mathrm{mOsm} \cdot \mathrm{kg}^{-1}(\mathrm{y})$ in ordinate.

During this study 4 experiments were conducted :

i. Determination of the variation of the osmotic concentration in the haemolymph as a function of the medium salinity in juvenile shrimps reared at $28^{\circ} \mathrm{C}$. 
ii. Observation of the effect of a temperature drop on hypo-osmoregulation of the juvenile shrimp.

iii. Study of the effect of a temperature fall on the hypo and the hyper- osmoregulation of subadult shrimps.

iv. And finally a comparative study, between juvenile and subadult shrimps, of the effect of a temperature fall on their osmoregulation.

\subsection{Statistics}

One-way ANOVA followed by a Protected Least Significant Difference test (PSLD) were applied in the second and third experiment (Fig 3 and Fig 4) to determine differences between experimental groups. Variability of the data are given as confidence limits (Fig 3) or as standard error of the mean (Fig 4). Polynomial curves were fitted to illustrate changes in haemolymph osmolality with rearing water salinity at each temperature tested (Fig 2 and Fig 5). The statistical analysis were carried out using the software StatView ${ }^{\circledR}$ version $n^{\circ} .5$ (Abacus Concepts).

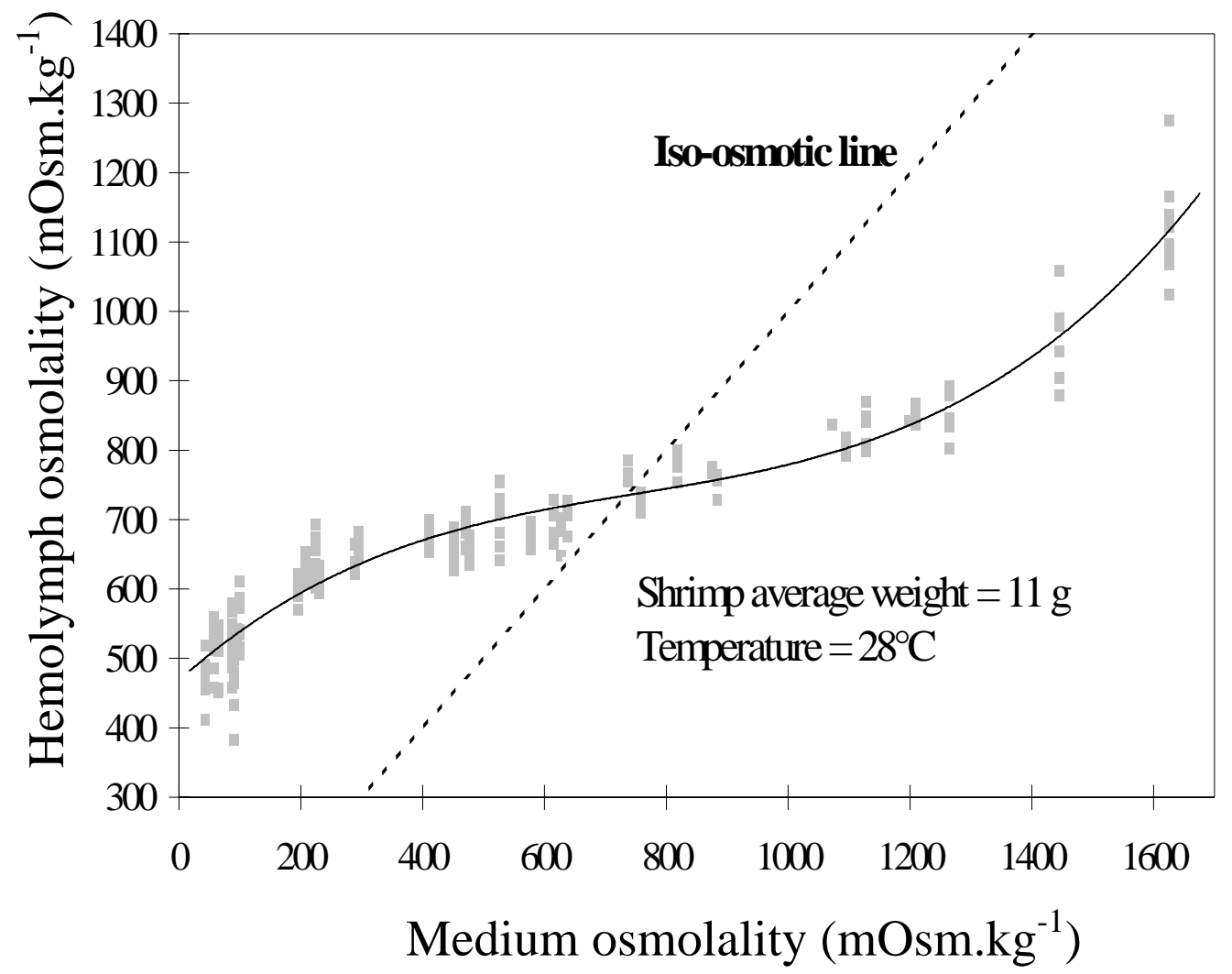

Fig 2. Haemolymph osmolality (solid line) as function of external osmolality in juvenile $\underline{P}$. Stylirostris reared at $28^{\circ} \mathrm{C}$ showing hypo-osmotic and hyper-osmotic regulation. The dotted line is the iso-osmotic line. The intersection between iso-osmotic line and the hyper-hypo regulation line corresponds to the iso-osmotic point. 


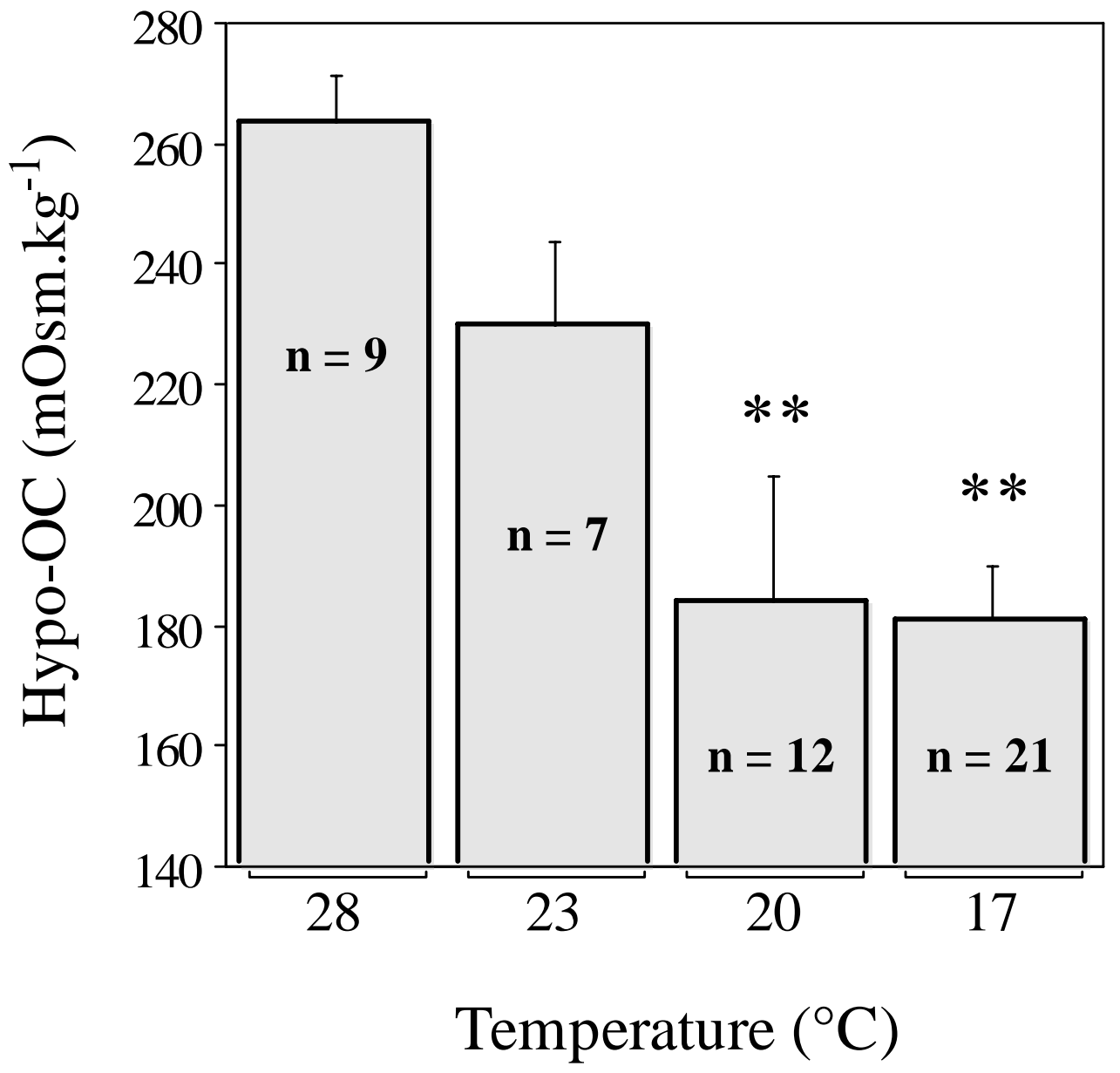

Fig 3. Hypo-osmoregulatory capacity (Hypo-OC) in juveniles of $\underline{\mathrm{P}}$. stylirostris following a temperature drop from $28^{\circ} \mathrm{C}$ and $24 \mathrm{~h}$ exposure to different temperature levels $\left(28^{\circ} \mathrm{C}, 23^{\circ} \mathrm{C}\right.$, $20^{\circ} \mathrm{C}$ and $17^{\circ} \mathrm{C}$ ) in sea water (35ppt; $986 \mathrm{mOsm} \cdot \mathrm{kg}^{-1}$ ). Mean values with $95 \%$ confidence intervals. Comparison with controls $\left(28^{\circ} \mathrm{C}\right):^{* *}(\mathrm{p}<0.001)$. 


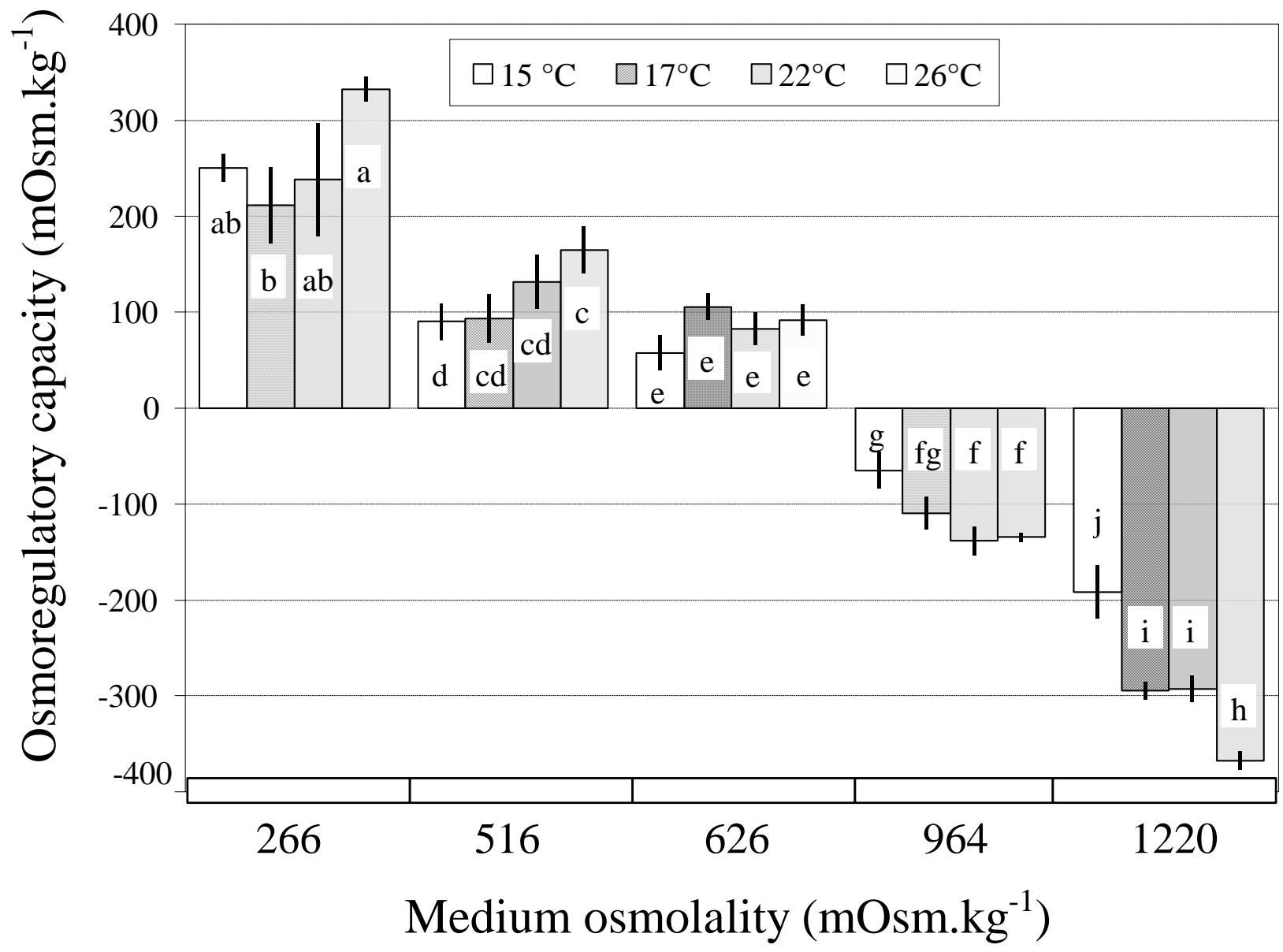

Fig 4. Osmoregulatory capacity (mean \pm SE, total $n=125)$ in subadult $\underline{P}$. stylirostris at different medium salinity expressed here as osmotic pressure and different temperature exposure. Letters show significance of data at the same medium salinity; different letters indicate a statisticaly significant difference $(\mathrm{P}<0.05)$. 


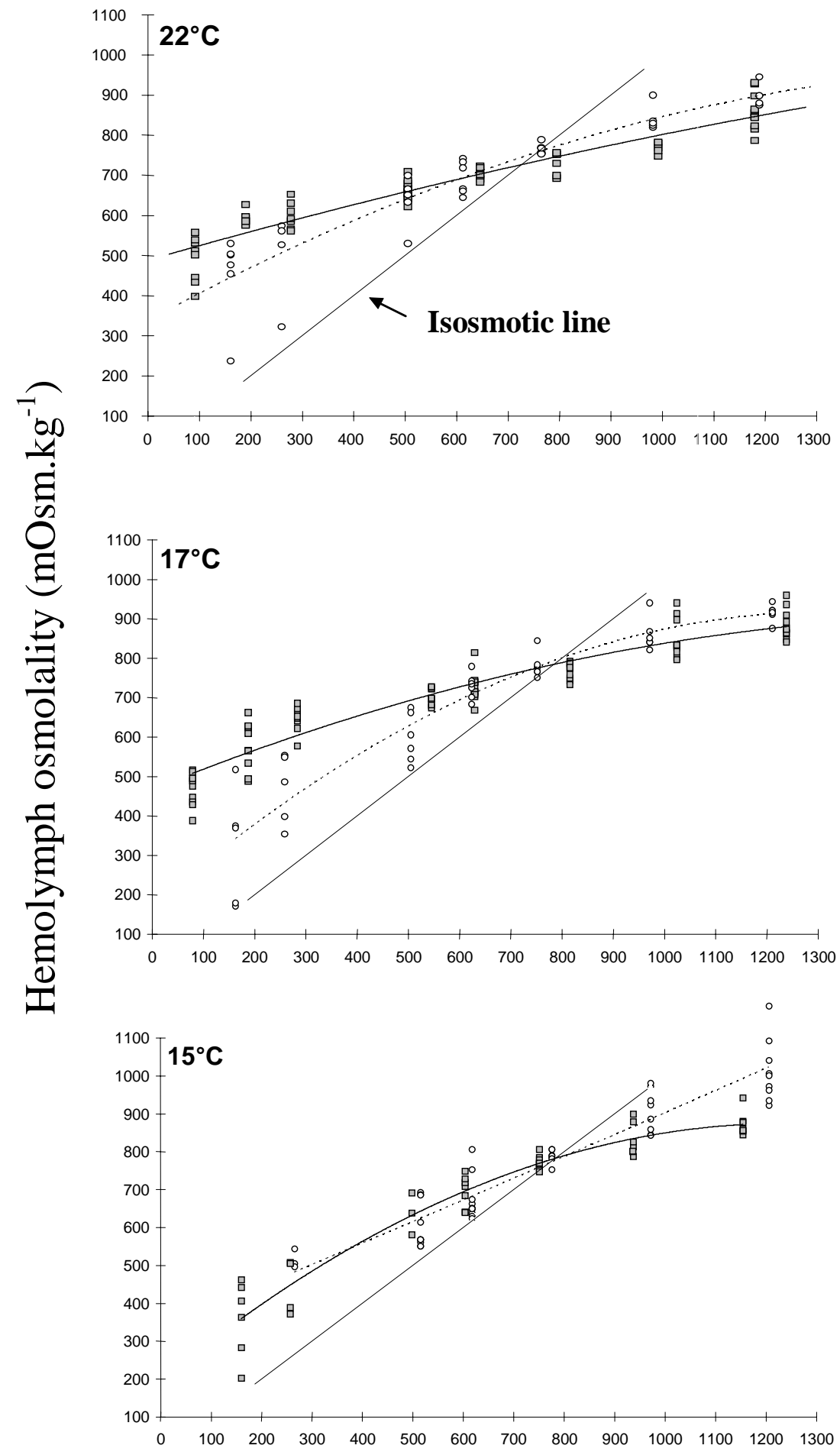

Medium osmolality (mOsm. $\mathrm{kg}^{-1}$ )

Fig 5. Comparison of the osmoregulatory profiles of juvenile (solid line) and subadult (dotted

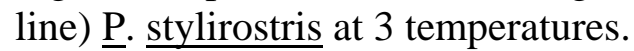




\section{Results}

\subsection{Osmoregulation in juvenile shrimps reared at $28^{\circ} \mathrm{C}$.}

The variations in haemolymph osmotic pressure measured in 229 juvenile shrimps $(10 \mathrm{~g} \pm$ $0.5 \mathrm{~g}$ of average weight) reared at $28^{\circ} \mathrm{C}$ as a function of rearing water osmolality are presented in Fig 2. The shrimps were clearly strong hyper-hypo osmoregulators. The hyperhyporegulation polynomial adjusted curve crosses the iso-osmolality line for a rearing water osmolality of $735 \mathrm{mOsm} . \mathrm{kg}^{-1}$ (corresponding to a salinity of $26.2 \mathrm{ppt}$ ). This value corresponds to the iso-osmotic point, below and above which the shrimp respectively hyper-regulated and hypo-regulated its haemolymph osmolality. Below $400 \mathrm{mOsm} . \mathrm{kg}^{-1}$ and above $1300 \mathrm{mOsm} . \mathrm{kg}^{-}$ ${ }^{1}$, the osmoregulatory capacity tends to become constant. At extreme salinities, the hyperhyporegulatory curve tends to parallel the iso-osmotic line.

\subsection{Effect of a temperature drop on the hypo-OC of juvenile shrimps.}

The haemolymph osmolality regulation was altered in juvenile shrimps (9.3 g $\pm 0.38 \mathrm{~g}$ ) exposed to a lower rearing temperature (Fig 3). Following a temperature drop of 5, 8 and $11^{\circ} \mathrm{C}$, the shrimp hypo-osmoregulatory capacity (hypo-OC) decreased by $13 \%$, $30 \%$ and $32 \%$ respectively ( $\mathrm{p}=0.0007)$. The decrease in osmoregulatory capacity was of the same magnitude in shrimps which underwent temperature drops of $8^{\circ} \mathrm{C}$ or $11^{\circ} \mathrm{C}$.

\subsection{Effect of a temperature drop on the hypo-OC and the hyper-OC of sub-adult shrimps.}

The shrimp (24.65 $\mathrm{g} \pm 0.41 \mathrm{~g}$ average weight) osmoregulatory capacity (OC) as a function of medium osmolality (Fig 4) was modified in a notable way by the drop in temperature. The pattern of OC tended to be reduced when temperature dropped. This phenomenon was accentuated in the low and high media salinity and even further at 43\% salinity. At this salinity, a limited fall of $4^{\circ} \mathrm{C}$ was followed by a significant decrease in the shrimp OC $(p=0.0327)$. At medium osmolalities close to the iso-osmotic value (26.2 ppt), the shrimp OC was less affected by the drop in temperature. At most of the tested salinities, the loss of the hypo-osmoregulatory capacity was accentuated in the shrimps subjected to a temperature of $15^{\circ} \mathrm{C}$.

\subsection{Comparative effect of temperature changes on the hyper-OC and hypo-OC in juvenile and sub-adult shrimps.}

Figure 5 represents the haemolymph osmolality pattern as a function of water osmolality in juvenile $(7.65 \mathrm{~g} \pm 0.31 \mathrm{~g})$ and sub-adult $(24.65 \mathrm{~g} \pm 0.41 \mathrm{~g})$ shrimps. At all the tested temperatures, the regulation of the haemolymph osmolality was more efficient in juveniles than in subadults. This superior osmoregulatory ability is illustrated by a hyper-hyporegulation curve more distant from the iso-osmotic line. The drop in temperature had a greater effect on the haemolymph osmolality regulation in sub-adult shrimps. The osmolality hyper-regulation curve of $25 \mathrm{~g}$ shrimps dropped in a notable way from $17^{\circ} \mathrm{C}$, whereas in $8 \mathrm{~g}$ shrimps, this phenomenon was only observed from a temperature of $15^{\circ} \mathrm{C}$ and below. Our results also indicate that a decrease in temperature has more effect on the haemolymph osmolality hyperregulation than on the osmolality hypo-regulation. While the change in hyper-OC is notable for sub-adult shrimps at $17^{\circ} \mathrm{C}$, it only occurs at $15^{\circ} \mathrm{C}$ and below for hypo-regulation.

At a given temperature, the iso-osmotic point is similar for juvenile and sub-adult shrimps. In contrast, the iso-osmotic point increased inversely with temperature, i.e. from 730 
m0sm.kg-1 to $800 \mathrm{~m} 0 \mathrm{sm} \cdot \mathrm{kg}^{-1}$ in the shrimps maintained at $22^{\circ} \mathrm{C}$ and $17^{\circ} \mathrm{C}$ (or $15^{\circ} \mathrm{C}$ ) respectively.

\section{Discussion}

The osmotic hyper-hypo regulation pattern of juvenile shrimps, $\underline{\text { P.stylirostris, }}$, reared at $28^{\circ} \mathrm{C}$ is typical of many brackish-water crustacea (Mantel and Farmer, 1983). The shrimps are respectively hypo-osmoregulators and hyper-osmoregulators, above and below the isoosmotic point. The iso-osmotic point determined at $28^{\circ} \mathrm{C}$ in this study was $735 \mathrm{mOs} . \mathrm{kg}^{-1}$, which corresponds to a rearing water salinity of $26.2 \mathrm{ppt}$. This value is higher than the one observed in the same species by Castille and Lawrence (1981) and Rodriguez (1981), i.e. 24ppt and 20-22 ppt respectively. We attribute these observed differences to different experimental conditions. In fact, we know that the biotic factors such as molt stage, nutritional state, size of the shrimps (Charmantier et al., 1994; Lignot et al.,1999), and abiotic factors, such as season (Dehnel, 1962; Charmantier, 1975), temperature (Williams, 1960; Charmantier-Daures et al., 1988; Chen and Lin, 1998), oxygen (Charmantier et al.,1994), ammonia (Lin et al.,1993) have an influence on the haemolymph osmolality control of the penaeid shrimps.

Our observations were conducted under standardized experimental conditions. These conditions allowed us to isolate the effect of temperature and to repeat the experiments.

In New Caledonia, the industrial farming of Penaeus stylirostris is growing rapidly with a total yield of $1906 \mathrm{mT}$ with 446 ha of ponds in culture, in 1999. However, since 1993, shrimp mass mortalities have been observed especially at the beginning of the cold season (May to June). Research carried out in New Caledonia and in Tahiti has attributed these mortalities to the bacteria Vibrio penaeicidae (Mermoud et al., 1998). However, mass mortality appears almost exclusively during the transitional seasons, when the average rearing water temperature drops (at the beginning of the cold season) or increases (at the end of the cold season). On top of these average water temperature variations, one must add the effect of nyctemeral fluctuations which can reach $7^{\circ} \mathrm{C}$ in 12 hours. Considering that the general change in temperature and the nyctemeral drop of the rearing water temperature can be associated with the occurrence of mortalities, we have investigated the influence of this parameter on the physiological state of the shrimp by measuring their haemolymph osmoregulatory capacity. Our observations clearly show the effect of a drop in temperature on the hypo-osmoregulatory capacity of the shrimp Penaeus stylirostris maintained at $35 \mathrm{ppt}$. There appears to be an inverse relationship between hypo-OC and sea-water temperature in the $28^{\circ} \mathrm{C}-20^{\circ} \mathrm{C}$ range. Under $20^{\circ} \mathrm{C}$ and down to $17^{\circ} \mathrm{C}$, hypo-OC remains constant. These observations are comparable with work done by Williams (1960) and Charmantier et al (1988) who

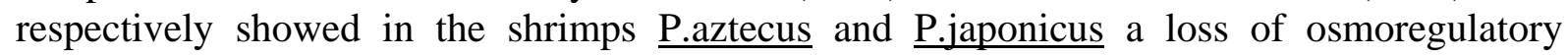
capacity following a drop in water temperature. Our observations of the shrimp haemolymph osmolality as a function of medium osmolality confirm the effect of a drop in temperature on osmotic homeostasis and provide additional information :

i. The rearing water temperature drop reduced the absolute value of the osmoregulatory capacity at all salinity levels studied. The impairment of osmoregulatory efficiency is greater at low salinity (10 ppt) and at high (43 ppt) salinity.

ii. Comparison of the osmoregulatory regulation showed a greater sensitivity of the subadult than juvenile shrimps to a temperature fall. The higher capacity of juvenile shrimps to osmoregulate following a temperature drop can be related to the results obtained by Lignot et al.(1999) which showed in the same species an increase of the absolute hypo-OC with the decrease of the shrimp wet weight. This relation has already been observed by other 
researchers (Williams, 1960, Castille and Lawrence, 1981; Vargas-Albores and Ochoa, 1992) and tends to confirm that the lower sensitivity of the osmotic regulation of the juvenile shrimps could be an adaptive response which allows them to live in habitats with significant temperature variations.

The iso-osmotic point reported in this study is the same for the juvenile shrimps and the sub-adults. The value of this point increases in the shrimps subjected to a drop in temperature greater than $7^{\circ} \mathrm{C}$. This observation confirms that made by Charmantier et al (1988) and Chen and Lin (1988) respectively in P.japonicus and P.chinensis. The significance of this inverse relationship between the value of the iso-osmotic point and temperature is not clear; it could be a disturbance in the hemolymph osmolality regulation mechanism due to the incapacity of the shrimps to acclimitize to our experimental conditions.

In conclusion, our observations provide an additional explanation for the "syndrome 93". The decrease in temperature of the culture water at the beginning of the cold season, and more generally the drastic temperature changes during the transitional seasons, affect the osmoregulatory capabilities of the reared shrimps. The shrimps, unable to maintain their homeostasis, could be weakened and become more sensitive to pathogens. Therefore the "syndrome 93" could have two aetiologies : a well demonstrated infectious origin (Mermoud et al, 1998) and a possible environmental origin revealed in this study. The role of temperature in initiating "syndrome 93" must be confirmed by laboratory studies with bacterial challenge tests.

The results of our studies lead us to search for solutions to the "syndrome 93" which would include an improvement of the capacity of shrimps to adapt to cold water and to fluctuating temperatures. In this frame, we have already shown that a diet enriched with n-3 highly unsaturated fatty acids (n-3 HUFA) enhanced the osmoregulatory capabilities of shrimps exposed to a temperature drop (Chim and al., 2001). It is likely that increasing dietary n-3 HUFA, an essential crustacean nutrient, could lead to a better 'homeoviscous adaptation' (Sinensky, 1974) of the cell membranes especially in the gills which are the main osmoregulatory organ and as a consequence, a better adaptation of the shrimp to a sudden drop in temperature and salinity. Genetic selection could be a second way to improve the shrimp's adaptive capacity to environmental stress. Indeed, when faced with temperature and osmotic stress, some shrimp presented a superior adaptative osmoregulatory capacity than average. We have shown (results unpublished) that this superiority was preserved over several molt cycles. If this character is heritable, it could be used in a genetic improvement program toward the selection of shrimp that are more robust and resistant to variations in their rearing environment.

\section{Acknowledgments}

The authors gratefully acknowledge advice on the manuscript by Professor Guy Charmantier.

\section{References}

AQUACOP, 1984. Review of ten years of experimental penaeid shrimp culture in Tahiti and New Caledonia. J. World Maricul. Soc., 15, 73-91.

Castille, F.L., Lawrence, A.L., 1981. The effect of salinity on the osmotic, sodium and chloride concentrations in the hemolymph of euryhaline shrimp of the genusPenaeus comp. Biochem. Physiolo. 68A, 75-80.

Charmantier, G., 1975. Variations saisonnières des capacités ionorégulatrices de Sphaeroma serratum (Fabricius, 1787) (Crustacea, Isopoda, Flabellifera). Comp. Biochem. Physiol. A 50, 339-345. 
Charmantier G., M. Charmantier-Daures, Bouaricha N., Thuet P., Aiken D.E., Trilles, J.-P., 1988. Ontogeny of Osmoregulation and Salinity Tolerance in Two Decapod Crustaceans :

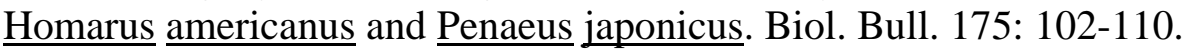

Charmantier-Daures M., Thuet P., Charmantier G., Trilles J.-P., 1988. Tolérance à la salinité et osmorégulation chez les post-larves de Penaeus japonicus et $\underline{P}$. chinensis. Effet de la température. Aqua. Living Resour., 1, 267-276.

Charmantier, G., Bouaricha, N., Charmantier-Daures, M., Thouet, P., Trilles, J.-P., 1989. Salinity tolerance and osmoregulatory capacity as indicators of the physiological state of peneid shrimps. European Aquaculture Society, Special Public., 10, 65-66.

Charmantier G., Soyez C., Aquacop, 1994. Effect of molt stage and hypoxia on osmoregulatory capacity of the penaeid shrimp Penaeus vannamei. J. Exp. Mar. Ecol. 178,233-246.

Chen J.-C., Lin J.-N., 1998. Osmotic concentration and tissue water of Penaeus chinensis juveniles reared at different salinity and temperature levels. Aquaculture 164, 173-181.

Chim L., Lemaire P., Delaporte M., Le Moullac G., Galois R., Martin J.L.M., 2001. Could a diet enriched with n-3 highly unsaturated fatty acids be considered a promising way to enhance the immune defences and the resistance of Penaeid prawns to environmental stress ?. Aquaculture research 32, 91-94.

Dehnel, P.A., 1962. Aspects of osmoregulation in the crab Hemigrapsus nudus. Can. J. Zool. 52, 923-937.

Drach P., Tchernifovtzeff, C., 1967. Sur la méthode de détermination des stades d'intermue et son application générale aux crustacés. Vie Milieu 18, 596-609.

Lignot J.-H., Cochard J.C., Soyez C., Lemaire P., Charmantier G., 1999. Osmoregulatory capacity occording to nutritional status, molt stage and body weight in Penaeus stylirostris. Aquaculture 170, 79-92.

Lin, H. P., Thuet, P., Trilles, J.-P., Mounet-Guillaume, R., Charmantier, 1993. Effect of ammonia on survival and osmoregulation of various development stages of shrimp Penaeus japonicus. Mar. Biol. 117, 591-598.

Mantel L.H., Farmer L.L., 1983. Osmotic and Ionic regulation. The Biology of Crustacea. Academic Press, Inc. 5, 53-161.

Mermoud I., Costa R., Ferré O., Goarant C., Haffner P. 1998. 'Syndrome 93' in New Caledonian outdoor rearing ponds of Penaeus stylirostris : history and description of three major outbreaks. Aquaculture 164 : 323-335.

Rodriguez G.A., 1981. Osmoregulation and total serum protein of two species of penaeidean shrimps from the Pacific coast of Mexico. Journal of Crustacean Biology. 1(3): 392-400 Williams, A.B., 1960. The influence of temperature on osmotic regulation in two species of estuarine shrimp (Penaeus). Biol. Bull. 115, 560-571.

Sinensky M., 1974. Homeoviscous adaptation - a homeostatic process that regulates viscosity of membrane lipids in Escherichia coli. Proceedings of the National Academy of Sciences, USA. 71, 522-525.

Vargas-Albores, F., Ochoa, J.L., 1992. Variation of pH, osmollality, sodium and potassium concentrations in the haemolymph of sub-adult blue shrimp (Penaeus stylirostris) according to size. Comp. Biochem. Physiol. A 102, 1-5. 
Williams, A.B., 1960. The influence of temperature on osmotic regulation in two species of estuarine shrimps (enaeus). Biol. Bull. (Woods Hole, MA) 119, 560-571. 